\title{
Haemophilus influenzae meningitis in Cuban children: a nineteen years follow up
}

\begin{abstract}
Background: Haemophilus influenza is a leading cause of community acquired bacterial meningitis and other infections, primarily in children $<5$ years. Here, we present the main features of $\mathrm{Hi}$ meningitis and analyze the effects of continuing and massive vaccination in Cuban infants and young children.
\end{abstract}

Methods: A 19 years observational study of 312 cases of Hi meningitis in children $<5$ years old was carried out (January $1^{\text {st }}, 1998$-December $\left.31^{\text {st }}, 2016\right)$. Incidence and case-fatality rate was estimated annually, by age and province, as well as monthly distribution.

Results: Overall incidence was $3.4 / 10^{5}$ population in infants (with biggest proportions at 6,4 and 7 months) and $1.4 / 10^{5}$ in young children, with marked decreasing trend in both. Study period case-fatality rate was near $13.7 \%$ in infants and around the half in young children with marked annually variations. All provinces decreased and maintain reduction of morbidity and mortality after vaccination.

Conclusion: Major decline in Hi meningitis morbidity and mortality confirmed the correctness and effectiveness of preventive strategy implemented in Cuba. Is worthwhile to continue the surveillance in order to identify changes in behavior of these life-threatening infections as well as circulating agents.

Keywords: Haemophilus influenzae, Hib, epidemiology, meningitis, infants, young children
Volume 8 Issue 3 - 2018

\author{
José R García,Waldemar Baldoquin, Misladys \\ Rodríguez, Félix O Dickinson \\ Department of Epidemiological Surveillance and Research \\ Tropical Medicine Institute Pedro Kourí, Cuba
}

Correspondence: Department of Epidemiological Surveillance and Research Tropical Medicine Institute Pedro Kourí, Autopista Novia del Mediodía, km. 6, municipio La Lisa, Havana, Cuba, Email dickinson@ipk.sld.cu

Received: May 28, 2018 | Published: June 07, 2018
Abbreviations: BMNSS, Bacterial Meningitis National Surveillance System; CFR, Case-fatality rate; CSF, Cerebrospinal fluid; Hi, Haemophilus influenzae; Hib, Haemophilus influenzae type b; NPPCINS, National Program for the Prevention and Control of Infectious Neurological Syndromes

\section{Introduction}

Despite the advances in antibiotic therapy and vaccines as wel as the availability of sophisticated intensive care reached in the past century and the ongoing, community acquired Bacterial Meningitis (CABM) remains a serious threat to global health due to its high rates of morbidity and mortality (especially in infants), ${ }^{1}$ the serious permanent sequels in survivors ${ }^{2}$ as well as the variability in causative bacteria. ${ }^{3}$ Three species, Streptococcus pneumoniae, Neisseria meningitidis and Haemophilus influenzae (Hi) are responsible for most cases of CABM occurring beyond the neonatal period, causing more than $80 \%$ of cases worldwide. ${ }^{4}$ Haemophilus influenza (Hi)is an important human pathogen that causes severe infections including meningitis, sepsis, bacteremia, pneumonia, sinusitis, epiglottitis and otitis mostly affecting young children. ${ }^{5}$ In the pre-vaccine era, $H$. influenzaeserotype $\mathrm{b}(\mathrm{Hib})$ was a leading cause of CABM, epiglottitis, and pneumonia, primarily in children under 5 years. Hib conjugate vaccines were introduced initially in the late 1980s for children aged 12 months or older, and later in the early 1990s for infants younger than 6 months old. Near elimination of Hib disease in children has occurred in countries that implemented pediatric Hib immunization programs. ${ }^{7}$ In Cuba Hib vaccination was introduced in 1999, decreasing the overall incidence of Hib meningitis from $1.3 / 10^{5}$ population in 1998 to $0.6 / 10^{5}$ population in $1999(53.4 \%$ reduction), with the greatest proportion in infants $(70.5 \%) .{ }^{8}$ After this intervention public health authorities decided to continue routine Hib vaccination through the National Immunization Program. ${ }^{9}$ The aim of this study was to describe the main features of Hi meningitis in infants and young children, as well as to analyze the effects of continuing and massive vaccination on infant's morbidity and mortality in the Cuban context.

\section{Methods}

This observational study was based on CABM surveillance data from January $1^{\text {st }}$, 1998 to December $31^{\text {st }}$, 2016. This includes 312 Hi meningitis reported cases in Cuban children under 5 years old, considering the date of the symptoms onset. The case definition for Hi meningitis was a clinical meningeal syndrome, through the identification of the causal agent directly by culture blood, petecchia, and cerebrospinal fluid (CSF) analysis or indirectly by polymerase chain reaction, latex test or another rapid diagnostic test at hospital level. ${ }^{10}$ The research was based on the information obtained from the Bacterial Meningitis National Surveillance System (BMNSS) questionnaires as part of the National Program for the Prevention and Control of Infectious Neurological Syndromes (NPPCINS) ${ }^{10}$ of the Republic of Cuba Public. The questionnaires provide uniform and truthful information throughout the country, ${ }^{11}$ allowing to consolidate a database for further analysis and interpretation. Incidence (cases $/ 10^{5}$ population) and case-fatality rate (CFR) by age (years old and months old), year and provinces were calculated using the Cuban population estimates of the National Bureau of Statistics. CFR was calculated as the proportion of fatality among cases per 100 . The present study was approved by the Scientific Board at Tropical Medicine Institute Pedro Kourí (IPK). The Cuban Ministry of Public Health is the governmental organization responsible for the collection of infectious 
disease notifications, hospital discharge records and population or laboratory surveillance. The management of these data for public health purposes does not require a patient's informed consent nor does it require any authorization regarding privacy laws in Cuba. For database compilation we used MS Excel 2007. For the data processing, statistical analysis and mapping we used $\mathrm{R}$ version 3.5.0 (2018-04-23), Epi Info 3.4 and Epidat 3.1 software.

\section{Results}

From January 1998 to December 2016, it was notified by the BMNSS a total of 2073CABMin children $<5$ years old, 1142 in $<1$ year old and 931 in 1-4 years old. Hi meningitis accounted 312 cases in children $<5$ years old, 131 cases in $<1$ year old and 181 in $1-4$ years old, representing 15.0, 11.4 and $19.4 \%$ among all cases of CABM in those age groups respectively (Data not shown). Annually, the major number of cases in infants was observed in 1998 (51) while in 1999 and 2000 accounted 14 each one. From 2001 to 2016 it was reported between 2 and 9 cases each year. It was not notified cases during years 2005, 2008 and 2013. The overall incidence in infants throughout1998-2016 was 5.4/10 $0^{5}$ population, with the highest numbers in 1998 , year before vaccination, 1999 (9.3/10 $0^{5}$ population) and $2000\left(9.8 / 10^{5}\right.$ population) continuing with lower figures. In 2015 a small peak was observed caused by 9 unrelated cases (incidence $7.2 / 10^{5}$ population) and then continue decreasing. The lowest incidence was observed in $2012\left(1.6 / 10^{5}\right.$ population) (Table 1). In children 1-4 years old the total of cases reported during the study period was 181, with highest figures in 1998 (77) and 1999 (42). In the remainder, the figures are between 1-12 cases annually and there was no reporting through years 2003, 2004 and 2007 (Table 1). Overall incidence of this age group was $1.4 / 10^{5}$ population during the period. Highest incidence was observed in 1998 (13.2/10 population), as also occurred in infants, followed by 1999 with $7.1 / 10^{5}$ population. The rest of the series showed rates between 0.2 and $2.4 / 10^{5}$ population (Table 1). (Figure 1) illustrate the annual incidence and trend along the study period in infants and children 1-4 years old, showing the important decrease starting in 1999 in both groups, but especially in the infants. Also a decreasing trend in both age-groups was evidenced $\left(\mathrm{y}=-0.6577 \mathrm{x}+11.551 ; \mathrm{R}^{2}=0.2403\right.$ and $\mathrm{y}=-0.297 \mathrm{x}+4.4979 ; \mathrm{R}^{2}=$ 0.2661 . respectively).

Effect of nationwide massive vaccination was evidenced in maps showed in (Figure 2). All provinces decreased their Hi meningitis incidence after vaccination. Comparison of proportional reduction in the overall incidence in 1999 to 2016 in infants and children 1-4 years old was $90.3 \%$ and $93.9 \%$ respectively. Between 1998 and 2016, it was notified a total of 301 deaths due to CABM in children $<5$ years old: 177 in $<1$ year old and 124 in 1-4 years old. Hi meningitis fatalities accounted 30 in $<5$ years old children, 18 cases in $<1$ year old and 12 in 1-4 years, representing 10.0,10.2 and $9.7 \%$ of all death due to CABM respectively (Data not shown). No deaths were reported during years 2002, 2004, 2008, 2010, 2012, 2013, 2015 and 2016. A total of 18 deceased reported in infants and 12 in children 1-4 years old, with lowest figures in the rest of the series (Table 2). During the period CFR in infants reached $13.6 \%$ and $6.6 \%$ in children 1.4 years old. In both groups it showed important variations in the figures with the highest in $2009(100.0 \%)$ in infants and 2001 and 2005 (50.0 $\%$ ) among children 1-4 years old (Table 2). Considering the age in months, no cases were reported among the infants below one month. The biggest numbers were observed at 6 months (22 cases), 4 months (17 cases) and 7 months (15) with the highest proportions respectively
$(17.3,13.4$ and $11.8 \%)$ ).In infants the biggest CFR was observed at 11 months $(80.0 \%)$, followed by the ages of 4 months (23.5\%), 10 months (22,2 \%) and 7 months (20.0\%) (Table 3).

Table I Cases and incidence rate of Haemophilus influenzae meningitis in infants and children I-4 years old. Cuba, 1998-2016.

\begin{tabular}{|c|c|c|c|c|}
\hline \multicolumn{3}{|l|}{ Infants } & \multicolumn{2}{|c|}{ Children I-4 years old } \\
\hline Year & Cases & Incidence & Cases & Incidence \\
\hline 1998 & 51 & 34 & 77 & 13.2 \\
\hline 1999 & 14 & 9.3 & 42 & 7.1 \\
\hline 2000 & 14 & 9.8 & 9 & 1.5 \\
\hline 2001 & 4 & 2.9 & 2 & 0.3 \\
\hline 2002 & 5 & 3.6 & 4 & 0.7 \\
\hline 2003 & 6 & 4.4 & - & - \\
\hline 2004 & 4 & 3.2 & - & - \\
\hline 2005 & - & - & 2 & 0.4 \\
\hline 2006 & 3 & 2.5 & 2 & 0.4 \\
\hline 2007 & 2 & 1.7 & - & - \\
\hline 2008 & - & - & 3 & 0.6 \\
\hline 2009 & 2 & 1.8 & 5 & I \\
\hline 2010 & 4 & 3.4 & 8 & 1.7 \\
\hline 2011 & 4 & 3.5 & 4 & 0.9 \\
\hline 2012 & 2 & 1.6 & 1 & 0.2 \\
\hline 2013 & - & - & 1 & 0.2 \\
\hline 2014 & 3 & 2.3 & 5 & I \\
\hline 2015 & 9 & 7.2 & 12 & 2.4 \\
\hline 2016 & 4 & 3.3 & 4 & 0.8 \\
\hline $1998-2016$ & $|3|$ & 5.4 & $|8|$ & 1.4 \\
\hline
\end{tabular}

Source: Bacterial Meningitis National Surveillance System from the National Program for the Prevention and Control of Infectious Neurological Syndromes. Incidence $10^{5}$ population

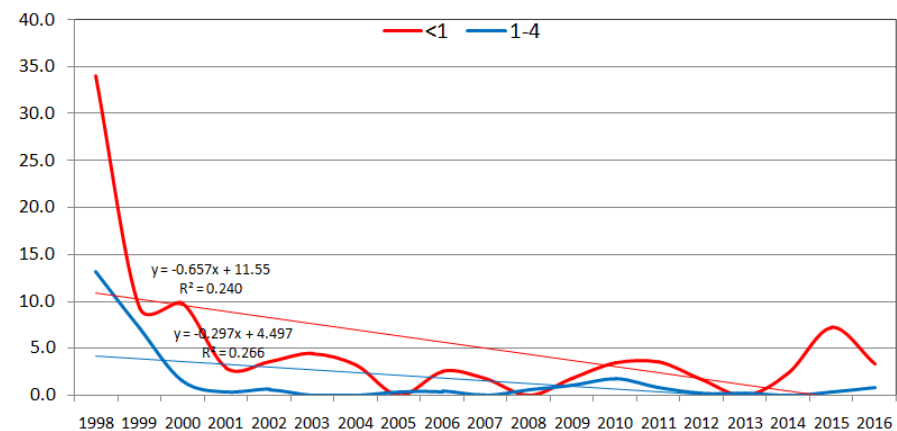

Figure I Annual incidence of Haemophilus influenzae meningitis in infants and children I-4 years old. Cuba, 1998-20I6. 
Table 2 Cases, deaths, incidence and case-fatality rate of Haemophilus influenzae meningitis in infants and children I-4 years old. Cuba, 1998-2016.

\begin{tabular}{lllll}
\hline Infants & & & \multicolumn{2}{l}{ Children I-4 years old } \\
\hline Year & Deaths & $\begin{array}{l}\text { Case-fatality } \\
\text { rate }\end{array}$ & Deaths & $\begin{array}{l}\text { Case-fatality } \\
\text { rate }\end{array}$ \\
1998 & 6 & 11.8 & 4 & 5.2 \\
1999 & 2 & 14.3 & 4 & 9.5 \\
2000 & 3 & 21.4 & $\mathrm{I}$ & $\mathrm{I} . \mathrm{I}$ \\
2001 & $\mathrm{I}$ & 25 & $\mathrm{I}$ & 50 \\
2003 & $\mathrm{I}$ & 16.7 & - & - \\
2005 & - & - & $\mathrm{I}$ & 50 \\
2006 & $\mathrm{I}$ & 33.3 & 0 & 0 \\
2007 & $\mathrm{I}$ & 50 & - & - \\
2009 & 2 & 100 & 0 & 0 \\
2011 & 0 & 0 & $\mathrm{I}$ & 25 \\
2014 & $\mathrm{I}$ & 33.3 & 0 & 0 \\
\hline $1998-2016$ & $\mathrm{I} 8$ & 13.7 & $\mathrm{I}$ & 6.6 \\
\hline
\end{tabular}

Source: Bacterial Meningitis National Surveillance System from the National Program for the Prevention and Control of Infectious Neurological Syndromes.

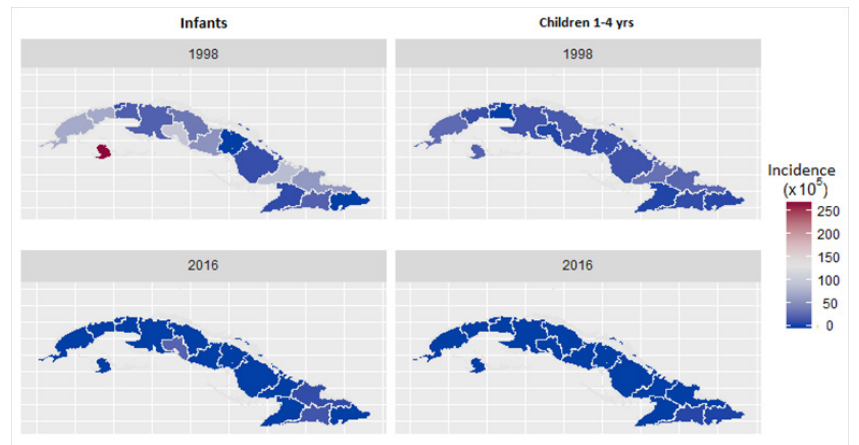

Figure 2 Annual incidence of Haemophilus influenzae meningitis in infants and children I-4 years old according to provinces. Cuba, 1998 and 2016.

Table 3 Cases, proportion, deaths and case-fatality rate of infants with Haemophilus influenzae meningitis by month of age. Cuba, 1998-20I6.

\begin{tabular}{lllll}
\hline Age (months) & Cases & $\%$ & Deaths & CFR \\
\hline-1 & - & - & - & - \\
1 & 1 & 0.8 & 0 & 0 \\
2 & 10 & 7.9 & 1 & 10 \\
3 & 8 & 6.3 & 1 & 12.5 \\
4 & 17 & 13.4 & 4 & 23.5 \\
5 & 13 & 10.2 & 2 & 15.4 \\
6 & 22 & 17.3 & 3 & 13.6 \\
7 & 15 & 11.8 & 3 & 20 \\
8 & 11 & 8.7 & 1 & 9.1 \\
9 & 11 & 8.7 & 1 & 9.1 \\
10 & 9 & 7.1 & 2 & 22.2 \\
\hline 11 & 10 & 7.9 & 8 & 80 \\
\hline
\end{tabular}

*Four cases did not report the age in months.

Source: Bacterial Meningitis National Surveillance System from the National Program for the Prevention and Control of Infectious Neurological Syndromes.

\section{Discussion}

This paper describes the main features of Hi meningitis in Cuba among young children and shows the effects of continuing nationwide massive vaccination on children's morbidity and mortality. There were some potential limitations to be considered and interpreted. First, our study was an observational retrospective design based on reports of the surveillance and, very few cases might have been missed or misdiagnosed despite the strict control of surveillance. Second, the BMNSS started the data collection in 1998; therefore the only previous information about the disease was that from the Mandatory Report of Diseases which since 1994 notified the disease, but do not included other information collected in BMNSS's questionnaires. Nevertheless, this report represents one of the largest, longest and deepest epidemiological studies on Hi meningitis registered in Cuba so far, and it was based on a nationwide surveillance which has been "useful and proficient providing and synthesizing critical and multidisciplinary information, fulfilling all suitable surveillance system attributes", ${ }^{11}$ ensuring reliability of data. Finally, our research includes a geographically well-defined population, with standard nationwide public health system. In 1993 Hib was competing very closely with pneumococcus for the first place as a cause of CABM among children under 5 years old. In infants during 1994 it was the main causative bacteria of CABM, with an incidence rate of $32.2 / 10^{5}$ population, increasing to $39.8 / 10^{5}$ population in 1997 . Likewise, in the group of 1-4 years old increase from $9.1 / 10^{5}$ population to $13.9 / 10^{5}$ population $^{12}$ In addition, it is noteworthy to comment the important number of Hi meningitis cases reported in Cuba during 1998, exceeding pneumococcus and meningococcus as leading bacteria causing CABM. ${ }^{13}$ Incidence curves in infants and children under 5 years old drops sharply in 1999 after vaccination similarly to those observed in countries which has implemented Hib vaccination. ${ }^{14-16}$ Nevertheless, in the present study, the incidence in infants is slightly greater to that of the children 1-4 years old, as well as CFR. Regarding elevated CFR observed in our study, it might be the effect of the drastic decrease in number of cases. Further studies will be needed to explain and confirm this premise. On the other hand, it has been suggested that vaccinated cases did not experience a milder disease attributable to the vaccine ${ }^{17}$ andmeningitis deaths might be preventable with existing Hib vaccines. ${ }^{18}$ Cuba implemented vaccination against Hib with conjugate vaccine (Vaxem-Hib ${ }^{\circledR}$ (Chiron Vaccines S. p. A., Italia) following two different tactics simultaneously (campaign followed by routine program) targeting children under 2 years old and high coverages. ${ }^{19}$ The sharp decline of meningitis caused by this pathogen immediately after vaccination (1999) occurred concurrently to arise in pneumococcal meningitis incidence, not fully explained, but probably due to the fast and intense decline of $\mathrm{Hi}$ meningitis, which might be opening a niche for pneumococci, increasing their carriage in population and therefore the exposure and likelihood to infection and disease as mentioned by authors. ${ }^{20}$ Previous studies carried out nationwide in Cuba, evidenced that despite vaccination against Hib, serotype $b$ continue to be the most frequent isolated ( $>90 \%) .{ }^{21}$ During the study period it was evident the effect of vaccination in reduction of morbidity in infants and children. After the Cuban conjugate vaccine Quimihib $^{\circledR}$ comply satisfactorily safety and efficacy trials, ${ }^{22}$ it was ready for using in prevention and control of Hib meningitis. For that reason Public Health Ministry introduced in the National Immunization Program since 2005, substituting Vaxem-Hib ${ }^{\circledR}$. This Cuban conjugate vaccine is the only made by chemical synthesis in the world and has shown high efficacy comparable to other available conjugate vaccines. ${ }^{22}$ In 2010 it was added to the Cuban pentavalent. ${ }^{23}$ 
Along the study period it was evident the effect of vaccination (both conjugate vaccines) in reduction of morbidity and almost eliminate the disease in infants and young children. Results in morbidity and mortality confirmed how effective and correct has been the preventive strategy against Hib implemented in Cuba. Also is worthwhile to continue the surveillance of disease in order to detect changes in behavior and circulating agents.

\section{Acknowledgements}

We are grateful to all colleagues at national and provincial level of the Bacterial Meningitis Surveillance System and the National Program for the Prevention and Control of Infectious Neurological Syndromes for their interest and effort in collecting and providing important information.

\section{Conflict of interest}

The author declares there is no conflict of interest.

\section{References}

1. Lucas MJ, Brouwer MC, van de Beek D. Neurologicalsequelae of bacterial meningitis. $J$ Infect. 2016;73(1):18-27.

2. Edmond K, Clark A, Korczak VS, et al. Global and regional risk of disabling sequelae from bacterial meningitis: a systematic review and meta-analysis. Lancet Infect Dis. 2010;10(5):317-328.

3. van de Beek D, de Gans J, Tunkel AR, et al. Community-acquired bacterial meningitis in adults. $N$ Engl J Med. 2006;354(1):44-53.

4. van de Beek D, Brouwer M, Hasbun R, et al. Community-acquired bacterial meningitis. Nat Rev Dis Primers. 2016;2:16074.

5. Ulanova M, Tsang RSW. Haemophilus influenzae serotype a as a cause of serious invasive infections. Lancet Infect Dis. 2014;14(1):70-82.

6. Whittaker R, Economopoulou A, Dias JG, et al. Epidemiology of invasive Haemophilus influenzae disease, Europe, 2007-2014. Emerg Infect Dis .2017;23(3):396-404

7. Bath S, Bisgard K, Murphy T, Shutt K, et al. and Centers for Disease Control and Prevention (CDC), Progress toward elimination of Haemophilus influenzae type $\mathrm{b}$ invasive disease among infants and children-United States, 1998-2000. MMWR Morb Mortal Wkly Rep. 2002;51(11):234-237.

8. Dickinson F, Pérez A, Galindo M, et al. Impact of vaccination against Haemophilus influenzae type b in Cuba. Rev Panam Salud Publica. 2001:10(3):169-73.

9. Reed G, Galindo MA. Cuba's National Immunization Program. MEDICC Review. 2007;9(1).
10. Quintana I, Sotolongo F, Llop A, et al. Programa Nacional de Prevención y Control de los Síndromes Neurológicos Infecciosos. Havana; Ministerio De Salud Publica; 1999; 1-35 p.

11. Pérez AE, Dickinson FO, Rodriguez M. Community acquired bacterial meningitis in Cuba: a follow up of a decade. BMC Infectious Diseases.2010;10:130.

12. Dickinson FO, Pérez AE. Bacterial meningoencephalitis in Cuba. Rev Cubana Hig Epidemiol. 2001;39(2):86-94.

13. Dickinson FO, Pérez AE. Bacterial meningoencephalitis in Cuban Pediatric population:1998-2000. Rev Cubana Pediatr. 2002;75(2):106-14.

14. Ladhani S, Slack MPE, Heath PT, et al. Invasive Haemophilus influenzae disease, Europe, 1996-2006. Emerg Infect Dis. 2010;16(3):455-463.

15. Laupland KB, Schonheyder HC, Ostergaard C et al. Epidemiology of Haemophilus influenzae bacteraemia: A multi-national population based assessment. J Infect. 2011;62(2):142-148.

16. Lee EH, Miriam Corcino, Arelis Moore, et al. Impact of Haemophilus influenzae type $\mathrm{b}$ conjugate vaccine on bacterial meningitis in the Dominican Republic. Revista Panamericana de Salud Pública. 2008;24(3):161-168.

17. Monge S, Mollema L, de Melker H, et al. Clinical Characterization of Invasive Disease Caused by Haemophilus influenza Serotype b in a High Vaccination Coverage Setting. J Pediatric Infect Dis Soc. 2018.

18. Davis S, Feikin D Johnson HL. The effect of Haemophilus influenzae type $\mathrm{B}$ and pneumococcal conjugate vaccines on childhood meningitis mortality: a systematic review. BMC Public Health. 2013; 13(Suppl 3):S21.

19. Dickinson F, Pérez A, Galindo M, et al. Impact of vaccination against Haemophilus influenzae type b in Cuba. Rev Panam Salud Publica. 2001;10(3):169-173.

20. Auranen K, Mehtala J, Tanskanen A, et al. Between-strain competition in acquisition and clearance of pneumococcal carriage-epidemiologic evidence from a longitudinal study of day-care children. Am J Epidemiol. 2010;171(2):169-176.

21. Toraño G, Menéndez D, Llop A, et al. Haemophilus influenzae: Caracterización de aislamientos recuperados de enfermedades invasivas en Cuba durante el período 2008-2011. Vacci Monitor. 21(3):26-31.

22. Verez-Bencomo V, Fernández-Santana V, Hardy E, et al. A synthetic capsular polysaccharide vaccine against Haemophilus influenzae type b polysaccharide. Science. 2004;305(5683):522-524.

23. González M, Valcárcel M, Galindo MA. Inmunizaciones en Cuba. Rev Cubana Pediatr. 2009;81:48-52. 